\title{
Painless thyroiditis following mRNA vaccination for COVID-19
}

\author{
Nobuhiko Nakaizumi $^{1}{ }^{1} \cdot$ Shuji Fukata ${ }^{1} \cdot$ Takashi Akamizu $^{1}$ \\ Received: 17 September 2021 / Accepted: 23 December 2021 / Published online: 15 January 2022 \\ (c) The Author(s) 2022
}

Recently, cases of subacute thyroiditis and Graves' disease following coronavirus disease 2019 (COVID-19) vaccine immunization have been reported [1-4]. Herein, we present two cases of painless thyroiditis (PT) after the administration of the mRNA COVID-19 vaccine.

\section{Case 1}

A 38-year-old woman presented with palpitations 17 days after the first dose of the COVID-19 Pfizer-BioNTech vaccine and was referred to the Department of Internal Medicine, Kuma Hospital, Kobe, Hyogo, Japan, 26 days after vaccination. The thyroid gland was diffusely enlarged without tenderness on palpation. The thyroid function test revealed elevated free T4 of $4.08 \mathrm{ng} / \mathrm{dL}$ (normal, 0.9-1.7) and free $\mathrm{T} 3$ of $7.30 \mathrm{pg} / \mathrm{mL}$ (normal, 2.3-4.0), with a suppressed thyroid-stimulating hormone (TSH) level of less than 0.005 $\mu \mathrm{IU} / \mathrm{mL}$ (normal, 0.61-4.23). Antithyroglobulin antibody $(\mathrm{TgAb})$ and antithyroid peroxidase antibody (TPOAb) were positive, while antibodies to the TSH receptor (TRAb) were negative. Thyroid ultrasonography (USG) showed a heterogeneous, hypoechogenic, enlarged thyroid gland with an estimated thyroid volume of $27.3 \mathrm{~mL}$ and normal Doppler flow. Thyroid scintigraphy $\left({ }^{131} \mathrm{I}\right)$ showed a marked decrease in 3-h uptake rate to $1.3 \%$ (normal uptake: 5-15\%). Based on the clinical symptoms and laboratory examinations, the patient was diagnosed with PT. She was followed up closely without therapy, and she did not receive the second dose of the vaccine. When she visited our hospital 7 weeks after being vaccinated, she was relieved of the palpitations and her laboratory data had improved, as follows: free $\mathrm{T} 4$ was $1.86 \mathrm{ng} / \mathrm{dL}$, free T3 was $3.75 \mathrm{pg} / \mathrm{mL}$, and TSH was 0.010 $\mu \mathrm{IU} / \mathrm{mL}$. Fourteen weeks post-immunization, she had mild

Nobuhiko Nakaizumi

nakaizumi@kuma-h.or.jp

1 Department of Internal Medicine, Kuma Hospital, Kuma Byoin, Kobe, Hyogo, Japan hypothyroidism, and after 5 months, her thyroid function returned to normal without treatment. The patient's thyroid function tests during follow-up are shown in Table 1.

\section{Case 2}

The patient was a 59-year-old woman who received her second dose of the Pfizer-BioNTech mRNA vaccine for COVID-19 in July 2021. Ten days later, abnormal thyroid function was incidentally detected on a blood test. She was asymptomatic, and her physical examination results were unremarkable. The blood levels of thyroid function were as follows: free T4, $2.35 \mathrm{ng} / \mathrm{dL}$; free T3, $5.42 \mathrm{pg} / \mathrm{mL}$; and TSH, $0.01 \mu \mathrm{IU} / \mathrm{mL}$. TgAb was positive, and TPOAb and TRAb were negative. The thyroid USG examination revealed that the estimated thyroid volume was $17.9 \mathrm{~mL}$, while the thyroid gland was bilateral, heterogeneous, and hypoechoic with normal blood flow. Her 20-min technetium-99 m thyroid scintigraphy uptake was significantly reduced to $0.01 \%$ (normal uptake: $0.5-3.0 \%$ ) (Fig. 1), and she was subsequently diagnosed with PT. Five weeks after immunization, she was asymptomatic and her laboratory data had slightly improved. Two months post-vaccination, her thyroid function had normalized without medication. The laboratory findings are summarized in Table 1.

To the best of our knowledge, there have been few reports of PT after mRNA vaccination for COVID-19 [2, 4]. PT is regarded as a variant form of Hashimoto's thyroiditis (HT) because the histopathology of PT is similar to that of HT. Moreover, PT frequently displays high levels of antithyroid antibodies, while many PT patients have a family history of thyroid autoimmune disease.

In such cases, the thyroid gland is non-tender and painless. PT is characterized by transient thyrotoxicosis caused by destruction of the thyroid gland, resulting in excess levels of thyroid hormone [5]. This thyrotoxicosis improves spontaneously and is often followed by a hypothyroid phase and complete recovery. 
Table 1 Patient's thyroid function tests during follow-up

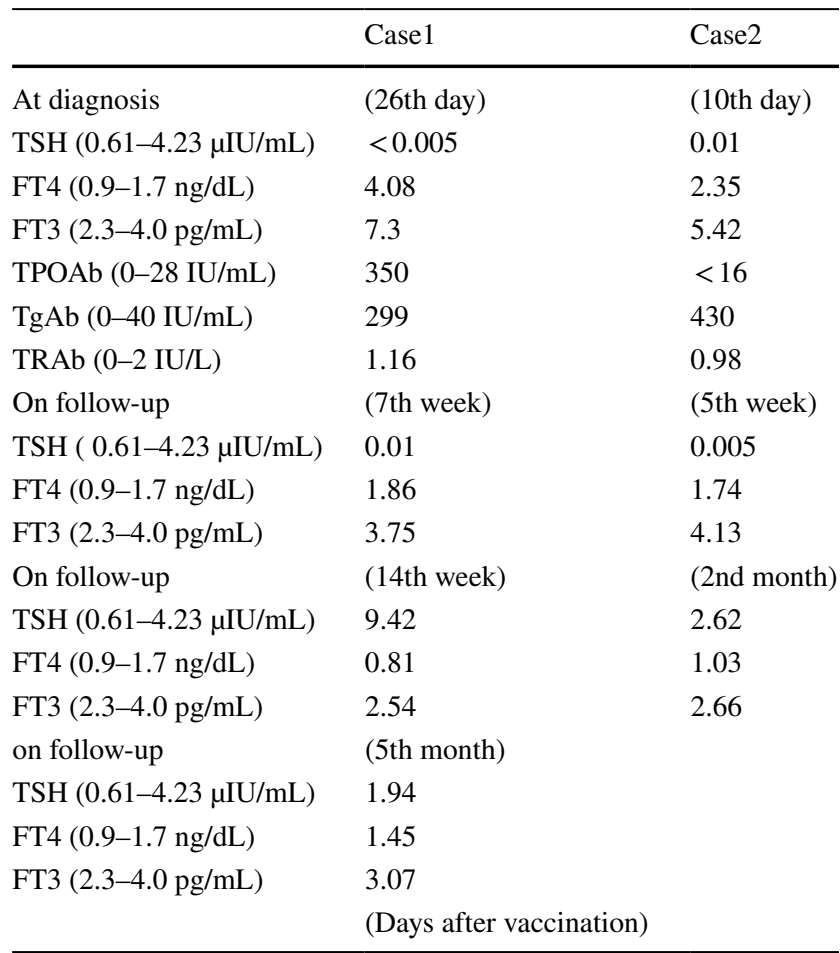

Abbreviations: TSH thyroid-stimulating hormone, FT4 free thyroxine, FT3 free triiodothyronine, TPOAb antithyroid peroxidase antibody, $T g A b$ antithyroglobulin antibody, $T R A b$ antibodies to TSH receptor

PT is considered to be an immune-mediated disorder and, as has been reported, may be caused by immune checkpoint inhibitor drugs, with various cytokines, such as interferonalpha and interleukin-2, being postulated to induce PT.

The condition of postpartum and cessation of glucocorticoids after adrenalectomy in patients with Cushing's syndrome, as well as other factors, are also reported to cause PT. Overall, it is assumed that these conditions cause thyroid inflammation and damage to the thyroid follicles, resulting in destructive thyroiditis [5].

Various vaccines to prevent severe acute respiratory syndrome coronavirus 2 (SARS-CoV-2) infection have been developed and are available for use. Some contain such adjuvants as aluminum hydroxide, toll-like receptor agonists, and potent Matrix-M1, among others, to enhance the immune response. However, these adjuvants can cause adverse immune reactions known as autoimmune/inflammatory syndrome induced by adjuvants (ASIA syndrome). The cases of subacute thyroiditis following inactivated COVID-19 vaccination have also been reported as an ASIA syndrome [3].

The Pfizer-BioNTech COVID-19 vaccine is an mRNA vaccine that does not contain any of these adjuvants. Nevertheless, cases of autoimmune thyroiditis meeting the criteria for ASIA syndrome have been reported after the use of this vaccine [4], suggesting that a component, or components, of the mRNA vaccine may serve as an adjuvant.

The mRNA vaccine has the potential to prevent SARSCoV-2 infection by producing a neutralizing antibody against the SARS-CoV-2 spike protein. However, the SARS$\mathrm{CoV}-2$ spike protein and TPO are structurally similar, and antibodies developed against SARS-CoV-2 may promote autoimmune thyroiditis [6]. Indeed, the case of a 13-year-old
Fig. 1 20-min technetium-99 m thyroid scintigraphy of case 2 . Thyroid gland uptake was significantly reduced to $0.01 \%$
TC-99m $20 \mathrm{~min} \quad 0.01 \%$

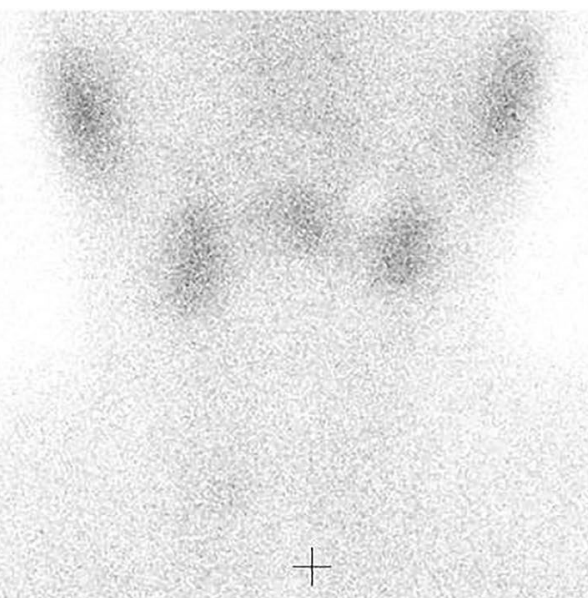

IV 
girl with a significant increase in TPO antibodies after Pfizer-BioNTech COVID-19 vaccination has been reported [7]. Thus, although there is a lack of definitive evidence, we suggest that PT could be caused by the autoimmunity triggered by the COVID-19 vaccine.

In conclusion, clinicians should be aware that PT may develop after the mRNA COVID-19 vaccination.

\section{Declarations}

Ethical approval Not applicable.

Informed consent The patients provided informed consent to publish of this report.

Conflict of interest The authors declare no competing interests.

Open Access This article is licensed under a Creative Commons Attribution 4.0 International License, which permits use, sharing, adaptation, distribution and reproduction in any medium or format, as long as you give appropriate credit to the original author(s) and the source, provide a link to the Creative Commons licence, and indicate if changes were made. The images or other third party material in this article are included in the article's Creative Commons licence, unless indicated otherwise in a credit line to the material. If material is not included in the article's Creative Commons licence and your intended use is not permitted by statutory regulation or exceeds the permitted use, you will need to obtain permission directly from the copyright holder. To view a copy of this licence, visit http://creativecommons.org/licenses/by/4.0/.

\section{References}

1. Vera-Lastra O, Ordinola Navaro A et al (2021) Two Cases of Graves' Disease Following SARS-CoV-2 Vaccination: An Autoimmune/Inflammatory Syndrome Induced by Adjuvants. Thyroid 31:1436-1439. https://doi.org/10.1089/thy.2021.0142

2. Siolos A, Gartzonika K, Tigas S (2021) Thyroiditis following vaccination against COVID-19: Report of two cases and review of the literature. Metabol Open 12:100136. https://doi.org/10.1016/j. metop.2021.100136

3. Iremli BG, Sendur SN, Unluturk U (2021) Three cases of subacute thyroiditis following SARS-CoV-2 vaccine: postvaccination ASIA syndrome. J Clin Endocrinol Metab 106(9):2600-2605. https:// doi.org/10.1210/clinem/dgab373

4. Pujol A, Gómez LA, Gallegos C, et al (2021) Thyroid as a target of adjuvant autoimmunity/inflammatory syndrome due to mRNAbased SARS-CoV2 vaccination: from Graves' disease to silent thyroiditis. Journal of Endocrinological Investigation [Epub ahead of print]. https://doi.org/10.1007/s40618-021-01707-0

5. Pearce EN, Farwell AP, Braverman LE (2003) Thyroiditis. N Engl J Med 348:2646-55. https://doi.org/10.1056/nejmra021194

6. Vojdani A, Vojdani V, Kharrazian D (2021) Reaction of human monoclonal antibodies to SARS-CoV-2 proteins with tissue antigens: implications for autoimmune diseases. Front Immunol 11:11089. https://doi.org/10.3389/fimmu.2020.617089

7. Buchhorn R, Meyer C, Schulze-Forster K et al (2021) Autoantibody Release in Children after Corona Virus mRNA Vaccination: A Risk Factor of Multisystem Inflammatory Syndrome? Vaccines 9:1353. https://doi.org/10.3390/vaccines9111353

Publisher's Note Springer Nature remains neutral with regard to jurisdictional claims in published maps and institutional affiliations. 